\title{
GREENERY SYSTEMS FOR URBAN SUSTAINABILITY: STATE OF THE ART AND PERSPECTIVE IN ITALY
}

\author{
ILARIA OBERTI \& FRANCESCA PLANTAMURA \\ Department of Architecture, Built Environment and Construction Engineering, \\ Politecnico di Milano, Milan, Italy
}

\begin{abstract}
The inclusion of greenery in our cities is a key factor for sustainability. Considering the shortage of green urban areas, building can play a positive role itself: through the inclusion of greenery systems (GS) such as green roofs and green walls, the building envelope can act as a multiplier of urban green surface. Nevertheless, despite the benefits achievable, GS implementation in the Italian context is still poor. The aim of this study is to produce the Italian state of art in terms of appreciation and promotion of GS solutions as urban quality agents and, on the other hand, in terms of the residual barriers to their spread. This framework can be used as a knowledge base for actions to encourage the adoption of GS in Italian cities. To this end, the study was carried out in three steps: review of GS benefits at urban scale; assessment of the Italian incentives for the GS diffusion; analysis of the current barriers to GS diffusion in the Italian context. The results show an extensive list of achievable benefits at the urban level (e.g. reduction of heat island, rainwater management, etc.) and their recognition in the Italian policies. Nevertheless, the study highlights a shortage in promotion tools, such as tax breaks, and the persistence of barriers to the GS spread (cost's gap between GS solutions and traditional; poor diffusion of GS technological culture). A greater commitment is hoped both in proposing effective incentives, both in a joint effort between administration and research in assessing benefits in relation to local needs and in spreading the technological culture of GS among professionals and consumers.
\end{abstract}

Keywords: green roof, green walls, sustainable city, policies, barriers.

\section{INTRODUCTION}

To date, the world population in urban areas has exceeded that of rural areas and, by 2050, more than $60 \%$ of the world's population is projected to be urban [1]. Urban areas are expanding, giving rise in industrialized country to an increase in both vertical dimensions and density [2]. Despite the urbanization is a major factor of social and economic development, the cities have also negative effects on environment, such as their huge emission of greenhouse gas (GHG), estimated about $70 \%$ of the world's energy related GHG emissions [3]. At the local level, cities are currently facing various environmental issues, such as urban air pollution and heat island. Moreover, the concreting is exacerbating the impact of weather events, increasing the environmental risk and generating synergetic effects for which "the impact in cities is larger than the sum of its parts" [4]. Finally, the environmental impact of cities has serious implications for the population with negative effects on health and wellbeing [5].

To cope with sustainability issues, one of the principles for cities' planning is the highdensity model [6], allowing higher levels of productivity and innovation and a lower per capita resource use and emissions. However, the high-density model cannot lead to more sustainable cities, if not combined with an attention in? the government and in the planning and design of urban land and its built environment. Particularly, with an urban development directed towards increasing density, the inclusion of greenery in our cities becomes a key factor for sustainability, mitigating the worst impacts for both environment and people and helping to manage the vulnerability to environmental risks. 
Many studies emphasize urban-nature relationships and promote the inclusion of greenery in cities [7], both as large areas (parks) and single elements in network (green infrastructure) [8]. This need of greenery in high-density cities clashes with the shortage of areas to be used for the introduction of vegetation. In this scenario, a positive role can be played from the building itself: through the adoption of Greenery Systems (GS), such as green roof and green walls, the external surfaces of the buildings can act as a multiplier of urban green surface. In this way, the greenery of buildings external surfaces can participate to form a wider network of urban green infrastructure, contributing to sustainability at the neighbourhood and urban scale (e.g. reduction of heat island, rainwater management).

Nevertheless, despite the benefits achievable, GS implementation in the Italian context is still poor. There are examples of best practices, even remarkable such as the Vertical Forest in Milan (Project: Boeri Studio). However, these solutions are not adopted in the common practice of building.

Considering the potential benefits of GS on urban environment and people, it becomes crucial to push their spread. The aim of this study is to produce an Italian state of art in terms of valorisation and promotion of GS solutions as urban quality agents and, on the other hand, to assess the residual barriers to their spread. This framework can be used as a knowledge base for actions to encourage the adoption of GS in Italian cities.

\section{METHOD}

The study was developed through the following three steps:

1. Review of urban benefits - Review of scientific literature concerning quantitative and qualitative research on Greenery Systems in order to highlight the results about their environmental and social benefits on a local base.

2. Assessment of incentives - Assessment of the Italian incentives for the GS diffusion in terms of addressing policies and financial supports.

3. Barrier analysis - Identification and analysis of the current barriers to GS diffusion in the Italian context.

For Greenery Systems (GS), this paper refers to any technological system that can be used to include greenery in building envelope, both vertical and horizontal [9]:

Green vertical surfaces

- Green facades and shields, direct or indirect (including a supporting system), based on the use of climbing plants without the technological complexity of living wall systems.

- Green walls, continuous or modular, self-sufficient systems (hydroponic green walls, green wall boxes), in which plants receive water and nutrients mainly from within a technological support (by drip irrigation system and fertilizer injector) instead from the ground.

\section{Green horizontal surfaces}

- Green roofs (also known as vegetated roofs, eco-roofs or living roofs), modular or monolithic extended surfaces, engineered setup of different high-performance layers that allow the growth of vegetation on rooftop.

o Extensive - with a shallow substrate $(<10-15 \mathrm{~cm})$, low growing succulent and/or herbaceous planting, generally not intended for human use. 
o Intensive - with substrate of about 20-60 $\mathrm{cm}$ depth often include planting of shrubs and trees and generally designed for human use.

o Modular - with plants self-contained within a lightweight high-density module, incorporating drainage, soil substrate and plant material into one unit.

- Green balcony, often including potted shrubs and small trees and generally designed for human use.

\section{RESULTS}

\subsection{Greenery Systems benefits at urban scale}

The introduction of greenery systems on the outer surface of the building allows a wide range of benefits for city's environment and population. Although there are some researches that show a poor efficiency of the GS, these are focused on single items. In example, with focus on energy saving performances, a research [10] shows that green vegetation could considerably reduce the negative heat transfer through the building facade in summer and winter months but it is not cost-effective in winter months or cold climatic regions. Actually, by focusing on a single item, the efficiency of a GS technology might not compete with that of a "gray" one. On the contrary, the GS can be competitive if regarding their whole benefits, since their greater efficiency lies in the ability to respond simultaneously to more environmental problems. Unfortunately, this does not facilitate the enhancement of the GS: environmental problems are often addressed by sectors (e.g. hydrogeological risk, on the one hand, air pollution, elsewhere, etc.), and so, from time to time, targeted "gray technologies" are promoted, losing sight of the possible global benefits achievable by choosing a GS.

Habitat - The more our cities grow, the more their environment moves away from the preurban ecosystem and continues to be impoverished of biodiversity. To oppose the negative effects on habitat, the most commonly used strategies are the preservation of natural areas still present in the urban area and the restoration of the degraded ones. An additional strategy is the "reconciliation ecology", finalized to "redesigning? human habitats to give some species back their geographical ranges without taking away ours" [11]. The introduction of green surfaces on the building envelope follows completely this principle, creating habitats, although of reduced dimensions, on the same land used by humans as living space [12]. These green islands can help in protecting wildlife and increasing wildlife diversity, both creating their own island habitats and working as "stepping stone" habitat in order to connect natural isolated areas. In case of green extensive roof, the substrate can be left to spontaneous colonization by plants and animals (Brown Roof), with a benefit for the variety of native species.

Urban heat island reduction - The term Urban Heat Island is used to indicate restricted areas (Warm Island) where the temperature is significantly higher than surrounding rural areas (Cool Sea). Multiple factors contribute to this phenomenon (e.g. the amount of heat due to the dissipation of a part of the energy required for urban activities). A serious factor is the replacement, in our cities, of most of the green surfaces with hard, dark surfaces. These surfaces are composed of high percentage of non-reflecting materials and tend to absorb a significant proportion of the incident radiation, then released as heat. Instead, greenery helps in cooling urban climates through shading and evapotranspiration. The use of GS contributes to increasing green urban surfaces in order to take advantage of the positive effect of vegetation in controlling the rising of local temperature [13], [14]. 
Raining management - In urban areas, the excess of waterproof surfaces significantly influences the modality of rainwater outflow, increasing the surface runoff rate than the intercepted flow from the ground. This leads to a significant stress of urban drainage basins, especially during extreme weather events. Numerous studies show that in our cities the use of green roofs is one of the best management practice for storm water, restoring a flow of rainwater similar to the natural one, which lowers and delaying the peak runoff and reduces risks of urban floods [15], [16].

Air pollution reduction \& human health -1 . Reduction of the emissions from air conditioning systems - In the summer, GSs are more powerful than a "gray" external wall insulation system, thus reducing the need for active air conditioning and the resulting emissions. This effect is determined through natural shading of the building envelope and cooling due to evapotranspiration of the GS vegetation. Moreover, particularly in the green roof, the growing medium and its water content increase the thermal inertia of building envelope [17]. 2. Removal of Air Pollutants - Plants, in particular trees, absorb gaseous pollutants through photosynthesis and intercept airborne particles in their leaves and branches, with a positive effect on health of local inhabitants. Many studies concern benefits that urban parks and tree stands roadside barriers produce in our cities [18], [19]. GS can contribute to this positive effect of urban vegetation. Rowe [20] estimates that one square meter of a green roof could offset the annual particulate matter emissions of one car. In order to improve air quality, intensive green roof and balcony are more favorable, because they allow installing trees and shrubs.

Attractiveness and stress reduction - From the second half of the last century, scientific studies in human science and design confirmed the intuitive positive correlation between nature and psychological wellbeing and the consequent attractiveness of nature in design [21], [22]. The adoption of GS, usable or at least visible by the population, helps in improving the attractiveness of local environment. Moreover, nature helps in coping and fast recovering from stress [23]. Many studies show evidences about the restorative power of green and express the need to increase the contact with green in urban environments [24], [25]. GS in contact with the local population can play an important role for this purpose, in our neighborhoods and cities increasingly devoid of natural environments.

Other social benefits - If usable by the local community, green roofs provide additional green space for local people, a great benefit in urban areas with limited green open space. In addition, green roofs, and even green walls, can accommodate edible plants, thus enabling the creation of urban vegetable gardens cultivated by the same citizens [26].

\subsection{Italian public incentives to GS diffusion}

The Italian policies recognize the role of GS as a part the urban green infrastructure in addressing emerging issues at local level, such as the cities' rising temperatures or the difficulty in managing meteorological events due to the low permeability of urban soils.

This recognition can be traced in general addressing policies, such as Law n.10 of the Italian Ministry of Environment [27] concerning the development of urban green spaces. In the section on the promotion of local initiatives (article 6), this law invites Regions, Provinces and Municipalities to promote solutions such as green roofs and green walls as strategies for: energy efficiency, absorption of fine particulate, reduction of the "summer heat island", regular collection of rainwater.

Nevertheless, "the lack in the law, of final deadlines, specific responsibilities, sanctions/penalties and substitution powers, undoubtedly disadvantages its practical 
application" [28]. The same approach can be traced in the other documents issued both at State level such as "The green infrastructure and ecosystem services in Italy" [29] and at local level, such as the drafting of the "Sustainable Urban Forestry Guidelines", prepared by ISPRA with Roma Capitale [30].

At State level, an incentive for the diffusion of GS comes from the policies addressed to achieve greater energy efficiency of buildings and to limit greenhouse gas emissions. The Italian legislation includes green roofs among the possible solutions to improve the energy efficiency of the building. So, since 2007 [31] green roofs can benefit from tax deductions that the Italian State, by acts issued year-by-year, grants for interventions for the energy retrofit of buildings. However, these incentives for the energy efficiency of buildings do not explicitly mention green roof solutions and the tax deduction is the same for both green and traditional solutions.

In this regard, the Italian Budget Law of 2018 is introducing an innovative "green bonus": a tax deduction of $36 \%$ on expenses incurred for work on green areas of uncovered private surfaces with a specific point about the "realization of green roof and roof gardens". The maximum spending limit is 5,000 euros for each building unit, to be divided into 10 annual shares of the same amount (which translates into a maximum deduction of 1,800 euros, with installments of 180 euros). For official confirmation, it is necessary to wait for the publication of the 2018 Budget Law.

At level of local policies, less than $20 \%$ of Municipalities introduced sustainability parameters for constructions in their own Building Regulations and, among these, those who explicitly mention the possibility to use of green roofs are few. Only 31 Municipalities, according to the last observatory report e-Lab [32], actively encourage this practice forcing to cover a part of the roof surfaces with green roofs in case of new construction or refurbishment.

Despite a general recognition of the environmental value of green roof, there is no accounting for their local collective benefit, which would be the first step for their enhancement. Moreover, local administrations do not always carry out an assessment of the environmental concerns of their area, which would be necessary to account for the local benefits of GSs. For example, the effect of "Rainwater Management" of a green roof will be of greater value in the case of heavily cemented urban settlements, even more if subject to extreme weather events. If this value is explicit, local administration will be more willing to introduce actions that encourage the installation of green roofs in its territory.

\subsection{Barriers to GS diffusion in Italian context}

Two major factors, closely related, emerge as barriers to the introduction of GSs. The first factor is the difference in cost between green and traditional technology solutions. The second factor is the incomplete dissemination of technological culture about the green envelope.

\subsubsection{Costs}

One of the major barriers to GS's spread is the cost that the private (enterprise, owner) must bear by choosing to install a GS.

Although it is difficult to point out an average price for GS solutions, which are quite different, some considerations can be made in terms of costs and benefits during installation and maintenance (Table 1).

A more accurate assessment is possible if we consider the solution of the "Extensive Green Roof" which, compared to other GSs, offers greater standardization. In the Italian market even for extensive solutions, the cost of a green roof is still quite high, with a gap between green and traditional solutions ranging from 50 to 80 euros per square meter. 
Table 1: GS costs and benefits during installation and maintenance.

\begin{tabular}{|c|c|c|}
\hline GS solution & Installation & Maintenance \\
\hline \multicolumn{3}{|c|}{ Green vertical surfaces } \\
\hline $\begin{array}{l}\text { Green facades / } \\
\text { shield }\end{array}$ & Lower installation costs. & $\begin{array}{l}\text { Possible damages of building } \\
\text { surface. } \\
\text { Difficulties in vegetation } \\
\text { continuity during plants } \\
\text { replacements. }\end{array}$ \\
\hline Green wall & $\begin{array}{l}\text { Higher installation costs. } \\
\text { Better integration of a wider } \\
\text { plants' variety. }\end{array}$ & $\begin{array}{l}\text { More rapid coverage of large } \\
\text { surfaces. }\end{array}$ \\
\hline \multicolumn{3}{|c|}{ Green horizontal surfaces } \\
\hline Extensive roof & $\begin{array}{l}\text { Lower installation costs. } \\
\text { Usable on flat surfaces, pitched } \\
\text { roof or curved surfaces. }\end{array}$ & $\begin{array}{l}\text { Lower costs of irrigation and } \\
\text { maintenance. }\end{array}$ \\
\hline Intensive roof & $\begin{array}{l}\text { Higher installation costs. } \\
\text { Usable mainly on flat surfaces. }\end{array}$ & $\begin{array}{l}\text { Higher irrigation and } \\
\text { maintenance costs. } \\
\text { Higher quality for human use. }\end{array}$ \\
\hline Modular roof & $\begin{array}{l}\text { Higher installation costs. } \\
\text { Easier installation. } \\
\text { Instant effect with pre-planted } \\
\text { materials. }\end{array}$ & $\begin{array}{l}\text { Lower maintenance and } \\
\text { installation costs. }\end{array}$ \\
\hline Green balcony & $\begin{array}{l}\text { Variable installation costs, also } \\
\text { depending on the selected plant } \\
\text { essences. }\end{array}$ & $\begin{array}{l}\text { Higher irrigation and } \\
\text { maintenance costs. } \\
\text { Higher quality for human use. }\end{array}$ \\
\hline
\end{tabular}

For the green roof, it is necessary to add specific functional layers to the ones of a traditional roof solution: root barrier, drainage and accumulation layer, filter layer, growing media, vegetation. Although some functional layers can be merged into one element, the costs do not drop considerably. For example, a producer sells a multi-functional mattress that includes drainage and filter layer at a price (about 10 euros per square meter) equal to the sum of the costs of the distinct layers offered by the same company. In this case, the advantage is, however, a reduction of the installing time and cost.

In Italy, the costs of green roofs, as well as the other GSs' coasts, will drop when the market is more mature. In fact, even now, equivalent solutions are cheaper in countries such as Germany, leader in green roof research and technology and with an estimated stock of around 86 million square meters by 2014 [33]. An example is a full package of 10 square meters of extensive green roof offered by a German company with a branch in Italy: the package is sold on the Italian market for a cost of 790 euros per piece while on the German market for a cost of only 420 euros per piece. 
While green roofs have higher installation costs than traditional solutions, the costs of maintenance and replacement are decreasing, because the additional layers of substrates and vegetation act as protection, increasing the roof longevity [34]. However, this benefit is only noticeable over the long term.

The gap in costs between a green roof and a traditional is not entirely covered by public incentives. National tax incentives for energy saving, as seen, are the same for both green and gray roof and do not value the additional benefits that green solutions bring to the city. A positive boost can be obtained from the "green bonus", introduced by the Budget Law 2018 , hoping that it will become a structural measure and not a one-off incentive.

\subsubsection{Technological culture}

Throughout the history of architecture, there are many examples of integration between buildings and vegetation. In recent years, these solutions have shifted from "unique objects" to standardized technology systems with well-defined technical specifications. The major companies that produce and market these solutions are spread mainly in northern Europe, the United States and Canada. In Italy, there are few companies operating in this sector and they are essentially spread in the north of the country. Most of these companies produce and distribute patented systems from other European companies, particularly German, while only a few of them offer their own systems.

In addition, the training of building industry professionals (construction companies and designers) on GS is still poor. With a good training on "gray" systems, the professionals are more reluctant to propose "green" solutions to the final customer, as they do not master them at the same level.

This immature market does not sufficiently boost the final customer to adopt a GS solution, nor does it provide enough reassurance to overcome doubts concerning the GS adoption (e.g. the load capacity of the pre-existing coverage, the possibility of water leaks, the maintenance costs of vegetation, etc.).

\section{DISCUSSION AND CONCLUSION}

The results show an extensive list of achievable benefits for the inclusion of greenery systems, even at the neighborhood level and urban, such as reduction of heat island, rainwater management and psychophysical wellbeing of local population.

The Italian policies recognize and promote the architectural greenery to both improve the energy quality of the building, and the urban environmental quality. The policy documents, however, lack in providing a compulsory in the time and manner of implementation and in incentives specifically directed to GS solution.

The analysis shows that a major barrier to the introduction of GSs is the difference in cost between green and traditional technology solutions.

In addition to the cost barrier, the diffusion of GSs in Italy is slowed down by the poor diffusion of technological culture on the green envelope.

Costs and low technology culture cause a low demand on the GS solutions market, slowing down the physiological reduction in market prices and the growth, even in knowhow, of Italian companies operating in the industry.

In conclusion, in order to stop this vicious circle and trigger a development in the GS sector, a greater commitment by the Italian public administration is hoped for in terms of incentives and / or mandatory measures.

At the same time, there is a need for a joint effort between public administration and the world of research in order to assess and account for the GS's benefits in relation to the 
environmental specificities of the different territories, and to spread the technological culture of GSs among industry players and consumers.

\section{REFERENCES}

[1] World Urbanization Prospects: The 2014 Revision; United Nations, Department of Economic and Social Affairs, Population Division: New York, 2015.

[2] UN-Habitat, Urbanization and Development - Emerging Futures. World Cities Report 2016, UN-Habitat Publication: Nairobi, 2016.

[3] World Resources Institute, The Global Protocol for Community-Scale Greenhouse Gas Emission Inventories, USA, 2014.

[4] Dan, L. \& Bou-Zeid, E., Synergistic Interactions between urban heat islands and heat waves: the impact in cities is larger than the sum of its parts. Journal of Applied Meteorology and Climatology, 52, pp. 2051-2064, 2013.

[5] The built environment and health: an evidence review; Glasgow Centre for Population Health (GCPH), Concepts Series 11 (2013), Briefing Paper, Online. www.gcph.co.uk/assets/0000/4174/BP_11__Built_environment_and_health_updated.pdf. Accessed on: Mar. $201 \overline{7}$.

[6] UN-Habitat, 2014, A new strategy of sustainable neighborhood planning: Five principles; World Resources Institute, Urban Planning Discussion Note 3, Online. www.unhabitat.org/a-new-strategy-of-sustainable-neighbourhoodplanning-fiveprinciples. Accessed on: 28 Mar. 2017.

[7] James, P., Towards an integrated understanding of green space in the European built environment. Urban Forestry \& Urban Greenery, 8(2), pp. 65-75, 2009.

[8] Koc, C.B., Osmond, P. \& Peters, A., Towards a comprehensive green infrastructure typology: a systematic review of approaches, methods and typologies. Urban Ecosystems, 20(1), pp. 15-35, 2017.

[9] Manso, M. \& Castro-Gomes, J., Green wall systems: A review of their characteristics. Renewable and Sustainable Energy Reviews, 41, pp. 863-871, 2015.

[10] Feng, H. \& Hewage, K., Energy saving performance of green vegetation on LEED certified buildings. Energy and Buildings, 75, 281-289, 2014.

[11] Rosenzweig, M.L., Reconciliation ecology and the future of species diversity. Oryx, 37(2), pp. 194-205, 2003.

[12] Francis, R.A. \& Lorimer, J., Urban reconciliation ecology: The potential of living roofs and walls. Journal of Environmental Management, 92, pp. 1429-1437, 2011.

[13] Gago, E.J., The city and urban heat islands: A review of strategies to mitigate adverse effects. Renewable and Sustainable Energy Reviews, 25, pp. 749-758, 2013.

[14] Price, A., Jones, E.C. \& Jefferson, F., vertical greenery systems as a strategy in urban heat island mitigation. Water Air Soil Pollution, pp. 226-247, 2015.

[15] Berndtsson, J.C., Green roof performance towards management of runoff water quantity and quality: A review. Ecological Engineering, 36, pp. 351-360, 2010.

[16] Carter, T. \& Jackson, C.R., Vegetated roofs for stormwater management at multiple spatial scales. Landscape and Urban Planning, 80, pp. 84-94, 2007.

[17] Vijayaraghavan, K., Green roofs: A critical review on the role of components, benefits, limitations and trends. Renewable and Sustainable Energy Reviews, 57, pp. 740-752, 2016.

[18] Tallis, M., Estimating the removal of atmospheric particulate pollution by the urban tree canopy of London, under current and future environments. Landscape and Urban Planning, 103, pp. 129-138, 2011. 
[19] Hagler, G.S.W., Field investigation of roadside vegetative and structural barrier impact on near-road ultrafine particle concentrations under a variety of wind conditions. Science of the Total Environment, 419, pp. 7-15, 2012.

[20] Rowe, B.R., Green roofs as a means of pollution abatement. Environmental Pollution, 159, pp. 2100-2110, 2011.

[21] Wilson, E.O., Biophilia: The Human Bond with Other Species, Harvard University Press: Cambridge, MA, 1984.

[22] Kellert, R.S., Heerwagen, J. \& Mador, M., Biophilic Design: The Theory, Science and Practice of Bringing Building to Life, John Wiley and Sons: Hoboken, NJ, 2008.

[23] Ulrich, R.S., Stress recovery during exposure to natural and urban environments. Journal of Environmental Psychology, 11(3), pp. 201-230, 1991.

[24] Kaplan, S., The restorative benefits of nature: toward an integrative framework. Journal of Environmental Psychology, 16, pp. 169-182, 1995.

[25] Roe, J.J., green space and stress: evidence from cortisol measures in deprived urban communities. International Journal of Environmental Research and Public Health, 10, pp. 4086-4103, 2013.

[26] Whittinghill, L.J. \& Bradley, D.R., The role of green roof technology in urban agriculture. Renewable Agriculture and Food Systems, 27(4), pp. 314-322, 2012.

[27] Italian Ministry of Environment, Law no.10 - Norme per lo sviluppo degli spazi verdi urbani, 2013.

[28] Annual report of the Committee for the Development Of Public Green - 2016; Italian Ministry of Environment, Committee for public green with the support of Ispra. www.isprambiente.gov.it/files/comitato-verde-pubblico/Relazione2016_rev15.pdf. Accessed on: Mar. 2017.

[29] Italian Ministry of Environment, The green infrastructure and ecosystem services in Italy. Final Report for the National Conference La Natura dell'Italia. Biodiversità e Aree protette: la green economy per il rilancio del Paese, December 11-12, Roma, 2013.

[30] Guidelines of Sustainable Urban Forestry for the Municipality of Rome - 2015; Ispra and Roma Capitale. www.isprambiente.gov.it/files/pubblicazioni/manuali-lineeguida/ GuidelinessuistainableurbanforestryROMA_Eng.pdf. Accessed on: 2017.

[31] Italian Government, Finance Act 2007 (Law no. 296, 2006 - art. 1, paragraphs 344349).

[32] L'innovazione nell'edilizia italiana - Rapporto 2016; Observatory report by e-Lab, promoted by Cnappc (Consiglio nazionale degli architetti) and Legambiente. www.legambiente.it/sites/default/files/docs/osservatorio_e-lab_innovazione edilizia.pdf. Accessed on: March 2017.

[33] EFB White Paper \& Market Report 2015; EFB (European Federation of Green Roof \& Wall). http://efb-greenroof.eu/wpcontent/uploads/2016/12/efb whitepaper_2015.pdf. Accessed on: Mar. 2017.

[34] Wong, N.H., Tay, S.F, Wong, R., Ong, C.L. \& Sia, A., Life cycle cost analysis of rooftop gardens in Singapore. Building and Environment, 38, pp. 499-509, 2003. 